\title{
Kesantunan Bahasa pada Buku Pelajaran Bahasa dan Sastra Indonesia untuk SMP/MTS Kelas IX
}

\section{Erna Tri Lestari ${ }^{凶}$, Bambang Hartono, Santi Pratiwi Tri Utami}

Jurusan Bahasa dan Sastra Indonesia, Fakultas Bahasa dan Seni, Universitas Negeri Semarang, Indonesia

\section{Info Artikel}

Sejarah Artikel:

Diterima Januari 2018

Disetujui Maret 2018

Dipublikasikan Juli 2018

\section{Keywords:}

Pragmatic; politeness; maxim of politeness; linguistic politeness; Bahasa dan Sastra Indonesia textbook for Junior High School/MTs class IX

\begin{abstract}
Abstrak
Penelitian ini bertujuan untuk mendeskripsikan mengenai pematuhan dan pelanggaran bidal-bidal kesantunan, serta kesantunan linguistik yang terdapat pada buku pelajaran Bahasa dan Sastra Indonesia untuk SMP/MTs Kelas IX.Pendekatan penelitian yang digunakan dalam penelitian ini adalah pendekatan teoretis dan metodologis. Pendekatan teoretis yang digunakan adalah pendekatan pragmatik, sedangkan pendekatan metodologis yang digunakan adalah pendekatan kualitatif dan deskriptif. Data dalam penelitian ini berupa penggalan wacana dantuturanpada buku pelajaran Bahasa dan Sastra Indonesia untuk SMP/MTs Kelas IX, sedangkan sumber data penelitian ini adalah wacana pada buku pelajaran Bahasa dan Sastra Indonesia untuk SMP/MTs Kelas IX. Pengumpulan data dilakukan dengan metode simak dan dengan teknik catat. Analisis data penelitian ini menggunakan metode normatif. Pemaparan hasil analisis data menggunakan metode informal. Hasil penelitian pada buku pelajaran Bahasa dan Sastra Indonesia untuk SMP/MTs Kelas IX ditemukan data yang bervariasi. Berdasarkan bidal-bidal kesantunan yang dipatuhi ditemukan pada bidal bidal kerendahatian, bidal kesetujuan, dan bidal kesimpatian. Berdasarkan bidal-bidal kesantunan yang dilanggar ditemukan pada bidal keperkenanan, bidal kesetujuan, dan bidal kesimpatian. Berdasarkankesantunan linguistik, ditemukan 3 data yang tergolong dalam panjang pendek tuturan sebagai penentu kesantunan linguistik tuturanimperatif, sedangkan padaungkapan penanda kesantunan linguistik tuturan ditemukan 27 data yang tergolong ke dalam tuturan yang mengandung ungkapan penanda kesantunantuturanimperatif dan tuturan yang tidak mengandung ungkapan penanda kesantunan yaitu pada ungkapan tolong, silakan, mari, ayo, dancoba.
\end{abstract}

\begin{abstract}
The purpose of this study is to describe the maxim-compliance and violation of maxim politeness, as well as linguistic politeness contained in Bahasa dan Sastra Indonesia untuk SMP/MTs Kelas IX textbooks. This study used theoretical and methodological approaches. The theoretical approach used is a pragmaticapproach, while the methodological approach used is qualitative and descriptive approach. The data in this study is a fragment of discourse on Bahasa dan Sastra Indonesia textbook for Junior High School/MTs class IX, while the source of data is a discourse on Bahasa dan Sastra Indonesia textbook for Junior High School/MTs class $I X$. Data collection is done with methods and techniques refer to the note. This data analysis using normative method. Exposure data analysis using informal method. The results of the study on Bahasa dan Sastra Indonesia textbook for Junior High School/MTs class IX was found the varies data. Based on maxim politeness complied found in modesty maxim, agreement maxim, and sympathy maxim. Based on maxim politeness infringed found on appobation maxim, agreement maxim, and sympathy maxim. Based on linguistic politeness, found 3 data belongs to the short-legth of the speech as a determinant of linguistic politenesss in speech, while the expression of linguistic speech politeness marker found 27 data that pertained to in the speech containing an exprssion of politeness markers and speech wich does not contain the phrase marker of politeness in that the expression please, please, let's, let's go and try.
\end{abstract}

(C) 2018 Universitas Negeri Semarang 


\section{PENDAHULUAN}

Bahasa digunakan oleh setiap manusia untuk berkomunikasi, saling bertukar informasi, pikiran, gagasan dan maksud yang ingin disampaikan. Selain menjalankan fungsinya sebagai alat komunikasi, bahasa juga bersistem, dalam berbahasa perlu menaati kaidah atau aturan bahasa yang berlaku. Berbahasa dengan baik dan benar tidak hanya menekankan kebenaran dalam hal tata bahasa, melainkan juga memperhatikan aspek komunikatif. Berbahasa secara komunikatif tidak selalu harus menggunakan bahasa standar. Sebaliknya, penggunaan bahasa standar tidak selalu berarti bahwa bahasa itu baik dan benar. Sebaiknya, kita menggunakan ragam bahasa yang serasi dengan sasarannya dan disamping itu mengikuti kaidah bahasa yang benar.

Berkomunikasi dengan bahasa tidak sekadar memahami dan dapat berbicara dalam bahasa yang digunakannya, tetapi ada prinsipprinsip yang perlu diperhatikan. Prinsip-prinsip yang dimaksud adalah kerukunan dan prinsip hormat. Prinsip kerukunan bertujuan untuk mempertahankan masyarakat dalam keadaan yang harmonis. Prinsip hormat menyatakan bahwa setiap orang dalam cara berbicara dan membawa diri selalu harus menunjukan sikap hormat terhadap orang lain sesuai dengan derajat dan kedudukannya Suseno (dalam Markamah 2014: 3).

Pemakaian bahasa harus baik dan benar, selain itu juga harus santun. Bahasa yang benar berkaitan dengan aspek kaidah, yakni peraturan bahasa. Berkaitan dengan peraturan bahasa, ada empat hal yang harus diperhatikan, yaitu masalah tata bahasa, pilihan kata, tanda baca, dan ejaan. bahasa yang santun merupakan bahasa yang dapat diterima oleh mitra tutur dengan baik. Banyak manusia yang sudah dapat berbahasa dengan baik bahkan sesuai dengan kaidah berbahasa, tetapi belum tentu dapat menggunakan bahasa secara santun. Seseorang dapat dikatakan santun apabila dapat menggunakan bahasa sesuai dengan situasinya dan tidak melanggar norma-norma yang ada.
Norma-norma kesantunan itu dijabarkan kedalam sebuah prinsip kesantunan. Prinsip kesantunan mengatur agar para peserta tutur dapat berbahasa secara santun dan tidak merugikan orang lain. Kesantunan berbahasa merupakan bagian dari kaidah-kaidah sosial dan kompetensi strategi berbahasa yang berperan penting dalam suatu proses komunikasi.

Pranowo (2012: 4) mengemukakan bahwa di dalam suatu struktur bahasa ( yang terlihat melalui ragam dan tata bahasa) terdapat struktur kesantunan. Sedangkan, menurut Grice (dalam Rustono1999: 61) prinsip kesantunan adalah prinsip yang berkenaan dengan aturan tentang hal-hal yang bersifat sosial, estetika, dan moral dalam bertindak tutur. Alasan dicetuskannya prinsip kesantunan adalah bahwa di dalam tuturan penutur tidak cukup hanya dengan mematuhi prinsip kerjasama dan mengatasi kesulitan yang timbul akibat penerapan prinsip kerjasama. Kemudian, prinsip kesantunan yang dikemukakan Leech (1983) didasarkan pada kaidah-kaidah. Kaidah-kaidah itu tidak lain adalah bidal-bidal yang meliputi: bidal ketimbangrasaan, bidal kemurahatian, bidal keperkenanan, bidal kerendahatian, bidal kesetujuan, bidal kesimpatian.

Selain prinsip sopan santun dalam berbahasa, pemakai bahasa juga perlu memperhatikan kaidah kebahasaan seperti kaidah sintaksis serta pola yang tidak boleh dilanggar agar tidak menyebabkan gangguan pada komunikasi yang terjadi.Rahardi (2005) menyatakan bahwa kesantunan linguistik tuturan imperative bahasa indonesia meliputi: panjang pendek tuturan sebagai penentu kesantunan linguistik tuturan imperatif, dan ungkapan-ungkapan penanda kesantunan linguistik tuturan imperatif. Secara sintaksis, setiap bahasa memilik kaidah sintaksisnya tersendiri.

Buku teks adalah buku yang digunakan dalam proses kegiatan belajar. Keberadaan buku teks dinilai penting bagi guru dan siswa. Bahan yang disajikan dalam buku teks berupa ilmu pengetahuan bidang tertentu. Oleh karena itu, isi 
dari buku tersebut harus bisa dipertanggungjawabkan kebenarannya menurut bidang studi yang bersangkutan. Buku ajar yang baik tentu memuat materi pembelajaran secara lengkap, tersusun baik, dan tidak mengandung hal-hal yang dapat menimbulkan gejolak yang tidak baik pada diri siswa. Dengan buku ajar yang baik, siswa dapat memperoleh informasi yang dibutuhkan dengan cara yang mudah. Pertimbangan memilih objek penelitian berupa buku pelajaran yang berjudul Bahasa dan Sastra Indonesia untuk SMP/MTs kelas IX karena dalam dunia pendidikan, buku merupakan bagian dari kelangsungan pendidikan. Buku pelajaran bahasa dan sastra indonesia tersebut akan diteliti dalam hal kelayakan bahasa.

Dipilihnya objek buku pelajaran Bahasa Indonesia dibandingkan dengan buku lain, karena di dalam buku Bahasa Indonesia memuat berbagai jenis teks baik itu cerita pendek, memahami dialog, membaca kutipan novel, pidato, syair dan lain-lain. Keunggulan buku teks Bahasa dan Sastra Indonesia dibandingkan dengan buku teks lain yaitu tedapat pada bagian isi buku, pada buku lain lebih banyak dimuat mengenai soal-soal latihan dan pemahaman, sedangkan pada buku teks Bahasa dan Sastra Indonesia terbitan PT Bumi Aksara memuat berbagai jenis bacaan sehingga data yang diperoleh bervariasi. Dalam bacaanbacaan tersebut tentunya terdapat tuturantuturan yang melanggar dan mematuhi bidal prinsip kesantunan yang menarik untuk diteliti. Selain meneliti tentang pelanggaran dan kepatuhan terhadap bidal-bidal prinsip kesantunan, peneliti juga akan melakukan penelitian dalam hal kesantunan linguistik yang berupa panjang pendek tuturan sebagai penentu kesantunan linguistik tuturan dan ungkapanungkapan penanda kesantunan linguistik tuturan imperatif.

\section{METODE PENELITIAN}

Pendekatan penelitian yang digunakan dalam penelitian ini adalah pendekatan teoretis dan metodologis. Pendekatan teoretis yang digunakan adalah pendekatan pragmatik, sedangkan pendekatan metodologis yang digunakan adalah pendekatan kualitatif dan deskriptif. Data dalam penelitian ini berupa penggalan tuturan pada buku pelajaran Bahasa dan Sastra Indonesia untuk SMP/MTs Kelas IX, sedangkan sumber data penelitian ini adalah tuturan pada buku pelajaran Bahasa dan Sastra Indonesia untuk SMP/MTs Kelas IX. Pengumpulan data dilakukan dengan metode simak dan dengan teknik catat. Analisis data penelitian ini menggunakan metode normatif. Pemaparan hasil analisis data menggunakan metode informal.

\section{PEMBAHASAN}

Deskripsi pembahasan yang akan dikemukakan pada bagian ini meliputi (1) pematuhan bidal-bidal kesantunan pada buku pelajaran Bahasa dan Sastra Indonesia untuk SMP/MTs kelas IX, (2) pelanggaran bidal-bidal kesantunan pada buku pelajaran Bahasa dan Sastra Indonesia untuk SMP/MTs kelas IX, dan (3) kesantunan linguistik tuturanimperatifpada buku pelajaran Bahasa dan Sastra Indonesia untuk SMP/MTs kelas IX

\section{Pematuhan Bidal-bidal Kesantunan pada Buku Pelajaran Bahasa dan Sastra Indonesia untuk SMP/MTs Kelas IX}

Berdasarkan penelitian ini, ditemukan tuturan yang mematuhi bidal kesantunan sebagai berikut.

(1) Bidal kerendahatian

KONTEKS :MASUT

MENGUCAPKAN

TERIMAKASIH

KEPADA GURUNYA

Masut :"Guru, terimaksih atas ilmu yang guru berikan kepadaku. Apalah artinya diriku andai tidak ada guru."

Guru :"Masut, Masut! Kamu harus tahu, meskipun kita mempunyai ilmu sedikit, namun tetap harus diberikan kepada orang lain."

(DATA 11)

Tuturan Apalah artinya diriku andai tidak ada guru." pada penggalan wacana di atas termasuk ke dalam 
tuturan yang mematuhi prinsip kesantunan bidal kerendahatian karena tuturan Masut meminimalkan pujian kepada diri sendiri dan memaksimalkan penjelekkan kepada diri sendiri

(2) Bidal Kesetujuan

KONTEKS :IRAH BERKATA KEPADA AYAHNYA BAHWA IA INGIN MENJADI PETANI BUNGA MAWAR

Irah :"Kini, setelah perlombaan selesai, saya akan konsentrasi pada tanaman mawarku."

"Saya akan menjadi petani bunga mawar."

Ayah :"Ayah mendukung sepenuhnya dan berjanji akan membantumu!"

(DATA 4)

Tuturan "Ayah mendukung sepenuhnya dan berjanji akan membantumu!" pada penggalan wacana di atas termasuk ke dalam tuturan yang mematuhi prinsip kesantunan bidal kesetujuan karena tuturan Ayah memaksimalkan kesetujuan dan meminimalkan ketidaksetujuan.

(3) Bidal Kesimpatian

KONTEKS :SARI MEMINTA

KEPADA IRAH AGAR TIDAK SEDIH LAGI KARENA IA AKAN MENGAJARINYA MEMBACA

Sari :"Jangan sedih, Irah!”

"Engkau pasti akan

mempunyai kebun mawar karena saya akan menolongmu. saya akan mengajarimu membaca setiap hari sampai kamu bisa membaca dan menulis."

Irah
sungguh?"

(DATA 3)

Tuturan “Jangan sedih, Irah!” pada penggalan wacana di atas termasuk ke dalam tuturan yang mematuhi prinsip kesantunan bidal kesimpatian karena tuturan Sari memaksimalkan kesimpatian dan meminimalkan antipati terhadap pihak lain.

Pelanggaran Bidal-bidal Kesantunan pada Buku Pelajaran Bahasa dan Sastra Indonesia untuk SMP/MTs Kelas IX

Berdasarkan penelitian ini, ditemukan tuturan yang melanggar bidal kesantunan sebagai berikut.

(1) Bidal keperkenanan

$\begin{array}{lr}\text { KONTEKS :TINI } & \text { MARAH } \\ \text { KEPADA SUAMINYA } & \text { KARENA } \\ \text { TIDAK } & \text { PERNAH } \\ \text { DIPERHATIKAN } & \end{array}$

Suami :"Bukan, kau bilang tidak usah menjemput?"

Tini :"Siapa bilang? Bukan kau yang mengatakan hendak menjemput aku?"

Suami

:"Bukan kau diam saja?"

Tini :"Perlukah aku buka mulut?

Mestikah aku menyembah-nyembah lagi? Mestikah berlututut di mukamu? Pasien, pasien, selamanya pasien, istrinya terlantar."

(DATA 13)

Tuturan "Perlukah aku buka mulut? Mestikah aku menyembah-nyembah lagi? Mestikah berlututut di mukamu? Pasien, pasien, selamanya pasien, istrinya terlantar." pada penggalan wacana di atas termasuk ke dalam tuturan yang melanggar prinsip kesantunan bidal keperkenanan karena tuturan Tini memaksimalkan penjelekkan terhadap pihak lain dan meminimalkan pujian terhadap pihak lain.

(2) Bidal kesetujuan

KONTEKS : DODI

MEMINTA AGAR ALAT BANTU PERNAPASAN AYAHNYA SEGERA DIPASANG 
Dodi :"Alat bantu pernapasan itu harus segera dipasang jika napas ayah berhenti."

Danar : :Jangan, jangan dulu! Kita harus tunggu ibu!" (setengah berteriak)

(DATA 10)

Tuturan "Jangan, jangan dulu! Kita harus tunggu ibu!" pada penggalan wacana di atas termasuk ke dalam tuturan yang melanggar prinsip kesantunan bidal kesetujuan karena tuturan Danar memaksimalkan ketidaksetujuan dan meminimalkan kesetujuan terhadap pihak lain.

(3) Bidal Kesimpatian

KONTEKS :TEMAN-TEMAN ANDI SEDANG MENANYAKAN TENTANG RENCANA KEBERANGKATAN MEREKA

Ali : "Gimana An, sudah siap? Ayo berangkat!'

Andi :"Maaf Al, ibuku sakit mendadak."

Arsad:"Ala, mengapa lu pikirin. Nanti juga kan sembuh sendiri."

(DATA 14)

Tuturan "Ala, mengapa lu pikirin. Nanti juga kan sembuh sendiri." pada penggalan wacana di atas termasuk ke dalam tuturan yang melanggar prinsip kesantunan bidal kesimpatian karena tuturan Arsad berusaha meminimalkan kesimpatian dan memaksimalkan antipati terhadap orang lain.

\section{Kesantunan Linguistik Tuturan Imperatif}

Berdasarkan penelitian ini, kesantunan linguistik yang terdapat pada buku pelajaran Bahasa dan Sastra Indonesia untuk SMP/MTs kelas IX, meliputi (1) panjang pendek tuturan sebagai penentu kesantunan linguistik tuturan imperative dan (2) ungkapan penanda kesantunan linguistik tuturan imperatif.
(1) Panjang Pendek Tuturan sebagai Penentu Kesantunan Linguistik Tuturan Imperatif KONTEKS :SEORANG PENGEMIS SEDANG MEMINTAMINTA KEPADA IBU-IBU YANG BARU SAJA KELUAR DARI RESTORAN

Pengemis :"Minta

sedekah, Nyonya!"

Ibu-ibu

$$
\text { :"Ini!" }
$$

Tuturan "Ini!" pada penggalan wacana di atas termasuk ke dalam tuturan pendek, dan dapat dikatakan kurang santun karena tuturan tersebut memiliki tingkat kelangsungan yang tinggi dan tidak menggunakan banyak basa-basi. Tuturan yang memiliki tingkat kelangsungan yang tinggi memiliki konotasi makna keras, tegas dan kasar. Selain itu, secara leksikal kata "Ini" merupakan kata penunjuk terhadap sesuatu yang letaknya tidak jauh dari pembicaraan. Dengan mengatakan "Ini!" penutur seolah-olah tidak menyukai kehadiran pengemis yang datang untuk meminta sedekah. Tuturan "Ini!" akan menjadi lebih santun apabila mendapat penambahan kata "Ambillah" sehingga menjadi "Ambillah ini!" karena dengan adanya penambahan kata "Ambillah" penutur secara sopan menyuruhnya untuk mengambil sesuatu yang akan Ia berikan.

(2) Ungkapan Penanda Kesantunan Linguistik Tuturan Imperatif

Ungkapan Mari

KONTEKS :PENULIS

MENGAJAK PEMBACA UNTUK MELUPAKAN DIET 
Tuturan :"Mari kita lupakan program diet kita teman!"

(DATA 37)

Tuturandi atas termasuk ke dalam tuturanimperatif yang santun karena dilekati oleh salah satu penanda kesantunan yaitu menggunakan penanda kesantunan mari. Secara leksikal kata "Mari" merupakan kata seru untuk menyatakan ajakan. Tuturan"Mari kita lupakan program diet kita teman!" dapat bermakna bahwa penutur mencoba mengajak mitra tutur untuk bersama-sama melupakan soal program diet yang sedang dijalaninya, tuturan tersebut seolah-olah diucapkan secara halus dan tanpa paksaan.

\section{Ungkapan Ayo}

KONTEKS :EMAK MENGAJAK UNTUK BERISTIRAHAT DI BAWAH POHON BESAR

Tuturan :"Ayo kita pergi ke pohon besar di sana itu!"

(DATA 31)

Tuturandi atas termasuk ke dalam tuturanimperatif yang santun karena dilekati oleh salah satu penanda kesantunan yaitu menggunakan penanda kesantunan ayo. Secara leksikal kata "Ayo" merupakan kata seru untuk mengajak atau memberikan dorongan. Tuturan"Ayo kita pergi ke pohon besar di sana itu!" dapat bermakna bahwa penutur mencoba mengajak mitra tutur untuk beristirahat. Tindakan tersebut tidak semata-mata dilakukan sendiri oleh penutur melainkan dilakukan bersama-sama dengan mitra tutur.

Ungkapan Coba

KONTEKS :PENULIS MENYURUH PEMBACA UNTUK MENCERMATI CONTOH BACAAN

Tuturan

\section{:"Coba}

cermati contoh berikut!"
(DATA 19)

Tuturandi atas termasuk ke dalam tuturanimperatif yang santun karena dilekati oleh salah satu penanda kesantunan yaitu menggunakan penanda kesantunan coba. Secara leksikal kata "Coba" merupakan kata yang digunakan untuk menghaluskan suruhan atau ajakan. Tuturan"Coba cermati contoh berikut!" merupakan tuturanimperatif yang bermakna halus, santun, dan sangat bijaksana. Dengan menggunakan bentuk ungkapan coba seolah-olah mitra tutur diperlakukan sebagai orang yang sejajar dengan penutur kendatipun pada kenyataannya, peringkat kedudukan diantara keduanya berbeda. Tuturan "Coba cermati contoh berikut!" dapat berarti bahwa penutur dalam hal ini penulis menyuruh pembaca secara halus untuk mencermati contoh dengan seolah-olah memperlakukan pembaca sebagai orang yang sejajar dengan penulis dan tidak memandang rendah pembaca.

Tidak Adanya Penanda Kesantunan Tolong

(33) KONTEKS

:PENULIS

MEMBERIKAN

SEBUAH

PILIHAN KALIMAT KEPADA PEMBACA

Tuturan :"Matikan lampu jika sudah tidak diperlukan!"

(DATA 23)

Tuturan di atas termasuk ke dalam tuturan imperatif yang kurang santun karena tidak dilekati oleh penda kesantunan, tuturan "Matikan lampu jika sudah tidak diperlukan!" dapat bermakna seolah-olah penutur menyuruh dengan paksa mitra tutur untuk melakukan apa yang diperintahkan. Dengan demikian, dapat dikatakan bahwa tuturan imperatif yang tidak dilekati oleh penanda kesantunan, memiliki 
peringkat kesantunan lebih rendah daripada tuturan yang dilekati penanda kesantunan. Tuturan tersebut akan menjadi santun apabila dilekati salah satu penanda kesantunan, sepertti tolong, sehingga dapat bermakna permitaan. Karena secara leksikal kata “Tolong” merupakan kata yang digunakan untuk meminta bantuan.

Tidak Adanya Penanda Kesantunan Silakan

(39) KONTEKS :PENULIS MENYURUH PEMBACA UNTUK BERLATIH MENGERJAKAN SOAL LATIHAN

Tuturan :"Gunakan bahasa
formal!"

(DATA 44)

Tuturan di atas termasuk ke dalam tuturan imperatif yang kurang santun karena tidak dilekati oleh penda kesantunan, tuturan "Gunakan bahasa formal!" dapat bermakna seolah-olah penutur menyuruh dengan paksa mitra tutur untuk melakukan apa yang diperintahkan yaitu menyuruhnya untuk menggunakan bahasa yang formal. Dengan demikian, dapat dikatakan bahwa tuturan imperatif yang tidak dilekati oleh penanda kesantunan, memiliki peringkat kesantunan lebih rendah dari pada tuturan yang dilekati penanda kesantunan. Tuturan tersebut akan menjadi santun apabila dilekati salah satu penanda kesantunan, seperti silakan, sehingga suruhan tersebut menjadi lebih halus. Karena secara leksikal kata "Silakan" merupakan kata yang menyatakan perintah secara halus.

\section{SIMPULAN}

Berdasarkan pembahasan tersebut dapat penulis simpulkan bahwa hasil penelitian meliputi: pematuhan bidal-bidal kesantunan ditemukan pada bidal bidal kerendahatian, bidal kesetujuan, dan bidal kesimpatian. Pelanggaran bidal-bidal kesantunan ditemukan pada bidal keperkenanan, bidal kesetujuan, dan bidal kesimpatian. Berdasarkan kesantunan linguistik, ditemukan 3 data yang tergolong dalam panjang pendek tuturan sebagai penentu kesantunan linguistik tuturanimperatif, sedangkan pada ungkapan penanda kesantunan linguistik tuturan imperatifditemukan 27 data yang tergolong ke dalam tuturan yang mengandung ungkapan penanda kesantunan dan tuturan yang tidak mengandung ungkapan penanda kesantunan yaitu ungkapan tolong, silakan, mari, ayo, dan coba.

\section{DAFTAR PUSTAKA}

Leech, Geoffrey. 1993. Prinsip-Prinsip Pragmatik. Jakarta: UI Press.

Markamah, et.al. 2014. Analisis Kesalahan dan Karakteristik Bentuk Pasif. Surakarta: Muhammadiyah University Press.

Pranowo. 2012. Berbahasa Secara Santun. Yogyakarta: Pustaka Pelajar.

Rahardi, R. Kunjana. 2005. Pragmatik Kesantunan Imperatif Bahasa Indonesia. Jakarta: Erlangga.

Rustono. 1999. Pokok-Pokok Pragmatik. Semarang: IKIP Semarang Press.

Suryaman, Maman, et.al. 2009. Bahasa dan Sastra Indonesia. Jakarta: Bumi Aksara. 